\title{
A Note on Family Influence and the Adoption of Discontinuous Technologies in Family Firms
}

JAMES J. CHRISMAN (corresponding author)

Department of Management \& Information Systems

Mississippi State University

Mississippi State, MS 39762-9581

jchrisman@ business.msstate.edu

and

Centre for Entrepreneurship and Family Enterprise

University of Alberta

HANQING FANG

Department of Management \& Information Systems

College of Business

Mississippi State University

Mississippi State, MS 39762, USA

E-mail: hf133@msstate.edu

and

China Small \& Medium Business Research Institute,

Zhejiang University of Technology, China

JOSIP KOTLAR

Institute for Entrepreneurship and Enterprise Development

Lancaster University Management School

Bailrigg, Lancaster, LA1 4YX, UK

E-mail: j.kotlar@lancaster.ac.uk

ALFREDO DE MASSIS

Institute for Entrepreneurship and Enterprise Development

Lancaster University Management School

Bailrigg, Lancaster, LA1 4YX, UK

\&

University of Bergamo, Italy

E-mail: a.demassis@lancaster.ac.uk

Accepted for publication in the Journal of Product Innovation Management 


\title{
A Note on Family Influence and the Adoption of Discontinuous Technologies in Family Firms
}

\begin{abstract}
In a recent article, König, Kammerlander, and Enders (2013) use Miller and Le Breton-Miller's (2005) 4Cs model of command, continuity, community, and connections to examine the effect of family influence on the adoption of discontinuous technologies. By assuming that family influence differs only in degree rather than kind, their model downplays the likelihood of heterogeneous behaviors among family firms. In this conceptual note, that assumption is challenged and König et al.'s work is extended by explaining how heterogeneity in the family's relative emphasis on command, continuity, community, and connections requires that the multifaceted and potentially non-linear nature of family influence be considered when analyzing strategic decisions concerning family firm innovation.
\end{abstract}


Family business studies must not only differentiate family from non-family firms but also explore heterogeneous behaviors within the family firm population (Chrisman et al., 2012). However, there remains a general tendency to oversimplify the nature of family influence, a tendency that restricts the understanding of the sources and consequences of heterogeneous family firm behavior. For instance, in a recent $A M R$ article, König, Kammerlander, and Enders (2013) examine the effect of family influence on the adoption of discontinuous technologies. They use the "4Cs model" of Miller and Le Breton-Miller (2005) to link the owning family's priorities toward command (current control of the firm), continuity (transgenerational sustainability of control), community (bonding social capital), and connections (bridging social capital) with decision-making in family firms. König et al. argue that family influence causes a shift in the organizational constraints typically faced by firms. Specifically, they propose that family influence leads to lower levels of formalization, resource dependence on external providers of capital, and political resistance. They also propose that family influence is associated with higher levels of emotional ties to existing assets and mental model rigidity among organization members. Based on these relationships they then propose that family influence will reduce the speed of recognition, aggressiveness, and flexibility of the adoption of discontinuous technologies but results in faster implementation and higher stamina if adoption does occur. Overall, König et al.'s model implies that family firms are less likely to adopt discontinuous technologies than non-family firms.

Despite its merits, König et al.'s model neglects important factors that cause heterogeneity in family firms and therefore provides only a partial understanding of how family firms respond to strategic choices such as the adoption of discontinuous technologies. In this conceptual note we review and then relax the critical assumptions used by König et al. with the 
aim of building on their work to develop research propositions on how the heterogeneity aspects of family influence affect the adoption of discontinuous technologies in family firms.

Critical Assumptions of König et al. (2013)

König et al. consider family influence to be "a continuous dimension, ranging from low to high, along which all companies can be arrayed” (2013: 421). Similarly, König et al. assume that the 4Cs are "reflective, covariant indicators of family influence" (2013: 422). Taken together these two assumptions are meant to assert that the 4Cs of family influence should increase or decrease together and that therefore they form a single construct that will have a consistent effect on family firm decision-making that depends solely on the level of influence. Assuming how much a family is able to influence firm behavior is determined solely and linearly by the degree of overlap between the family and business system is reasonable. However, to assume that how that influence is exercised can be captured by a single, linear construct is problematic since how family influence translates into firm behavior is likely to vary in type as well as degree according to the goals of key family stakeholders and their willingness to use their power to govern the firm in a particularistic way (Carney, 2005; Kotlar and De Massis, 2013). For example, Chrisman and Patel (2012) show that irrespective of a family's current control (command), the importance of the transgenerational sustainability of control (continuity) can vary among family firms and that this variation produces heterogeneous $R \& D$ investment decisions. Moreover, family influence is also a function of resources since fiat is ultimately shaped by the types and magnitude of the responses a firm is capable of producing and family involvement is thought to promote access to some resources and preclude access to other resources (Gedajlovic and Carney, 2010). Finally, when idiosyncratic family influence is exercised could also vary depending upon situational factors such as the imminence of intra-family succession, declining performance, or exogenous 
shocks. Such factors can lead to changes in goals and governance structures, and thus cause preference reversals that alter the behavior of family firms (Kotlar and De Massis, 2013; Patel and Chrisman, forthcoming).

Nonetheless, even the relationship between the degree of family influence and firm behavior might not be strictly linear for at least two reasons. First, one of the primary conclusions of Miller and Le Breton-Miller was that "each of the Cs, when taken to extremes has a sinister side: continuity becomes stagnation, community clannish insularity, connection dependence and command carelessness" (2005: 526). In the context of König et al.'s model, this suggests that moderate levels of family influence could produce higher (or even possibly lower) levels of discontinuous technology adoption than found in firms on the extremes of the family influence continuum, rather than medium amounts as a linear relationship would require.

Second, command, continuity, community, and connection are not necessarily positively related to each other and could also have divergent relationships with innovative activities, such as the adoption of discontinuous technologies. For example, the importance attached to command and continuity need not translate into comparable levels of regard for community in general (Verbeke and Kano, 2012), especially in environments with underdeveloped institutions (Ilias, 2006; Luo and Chung, 2013). Furthermore, Chrisman and Patel's (2012) findings suggest that the impact of command and continuity on R\&D investments are contradictory: greater family command tends to decrease such investments whereas the pursuit of continuity tends to increase them. Thus, given the potential for inconsistent and diverse relationships, which will be further discussed below, the combined influence of the 4Cs on discontinuous innovation will not necessarily be linear. 


\section{The Heterogeneity of Discontinuous Technology Adoption}

As implied above, from a conceptual point of view a potential reason for the discrepancy between König et al.'s (2013) theory and the empirical evidence is that they seem to focus most of their arguments on the family's power to command, assuming that as the power to govern the firm through control of ownership and management increases, so does the likelihood that a particular and predictable set of behaviors will follow. However, power only determines the ability to pursue goals, not what goals will be pursued. Rather, goals determine how power is used. Research and theory suggest that continuity is a chief goal guiding a family firm's actions (cf., Chrisman et al., 2012). Furthermore, community and connections are resources that are influenced by (and subsequently influence) the goals and governance structure enacted by the dominant coalition of decision makers. Thus, command is a necessary condition but not a sufficient condition for a family to exercise influence and only provides a partial understanding of the nature of the idiosyncratic behavior that is likely to occur (cf., Zellweger et al., 2012). How and when family owners and managers exercise their influence will also be a function of how much they value continuity; other factors, such as the stocks and flows of their investments in building community and connections with various stakeholders also come into play.

In the following sections an argument is presented that the heterogeneity of family firms comes from the governance structures used, the goals sought, and the resources available in both family and business systems. In addition, idiosyncratic situational factors that could produce preference reversals in family firms are also considered. By doing so, propositions that extend, and in some cases contradict Konig et al.'s work are developed. For illustrative purposes and to link these arguments more closely to König et al.'s model, propositions are framed according to the dimensions of command, continuity, community, and connections originally conceived by 
Miller and Le Breton-Miller (2005) and references to König et al.'s original propositions are italicized. Nevertheless, there are a number of equally useful alternative ways to capture the goals (e.g., socioemotional wealth: Berrone, Cruz, and Gomez-Mejia, 2012), governance (e.g., ownership configurations: Gersick et al., 1997), and resources (e.g., generic non-tradable assets: Gedajlovic and Carney, 2010) of family firms.

\section{The Governance Perspective: Family Command and Discontinuous Technology Adoption.}

If the family does not control the firm through some combination of ownership, management involvement, and board representation its ability to influence firm decisions and achieve familycentered goals is limited (De Massis et al., forthcoming). In this light, König et al.'s assumptions that family command is geared toward current control and therefore associated with lower formalization (because owners are already motivated and efficient monitors), resource dependence on external capital (because of a lack of pressure to grow as well as reluctance to share power or increase risk), and political resistance (because of concentrated ownership and management control), are acceptable. To expect that command will exacerbate any tendency on the part of owners and managers to develop emotional ties to assets and rigid mental models is also reasonable. Existing assets represent the fruits of the decisions of family owners, managers, or their predecessors and mental models that have worked and gone unchallenged are unlikely to change in the absence of an endogenous or exogenous shock. Thus, both König et al.'s model, and the findings of other studies (e.g., Chrisman and Patel, 2012), support the conclusion that command will reduce the adoption of discontinuous technologies by reducing the speed and aggressiveness of the process.

Proposition 1: The relationship between the degree of family command of a firm and the adoption of discontinuous technologies is negative. 
The Goals Perspective: Family Continuity and Discontinuous Technology Adoption. Family

firms may further vary owing to the array of goals pursued by organizational members (Kotlar and De Massis, 2013). For example, the relative importance of economic and non-economic goals can lead to heterogeneous outcomes because are often, but not necessarily, trade-offs between the achievement of those goals (Zellweger and Nason, 2008). Furthermore, there are a wide variety of possible economic and non-economic goals, and neither set is necessarily internally compatible. For example, sales growth does not always translate into profits and intrafamily succession does not always lead to an enhanced reputation or even family harmony.

One set of family-centered non-economic goals that has been highlighted in the literature is the family's intention to hand over the business to later generations. Given an intention for continuity, family-influenced firms may engage in behaviors that are more long-term than shortterm oriented, which is contradictory to the general conclusions drawn by König et al. In this regard, family owners may perceive the adoption of discontinuous technologies to contribute to the creation of economic and socioemotional wealth and, accordingly, increase family business continuity. In addition, continuity is often perceived as hierarchically more important than other family-centered non-economic goals (Chrisman et al., 2012; Kotlar and De Massis, 2013). Hence, given the possibility that maintaining continuity requires change and growth, the family may be willing to seek external funding, abandon existing assets, and make other strategic changes that will increase rather than decrease the recognition, aggressiveness, and flexibility of the adoption of discontinuous technologies, when these actions are perceived as increasing the odds for long-term survival.

Proposition 2: The relationship between the importance of family firm continuity and the adoption of discontinuous technologies is positive. 


\section{The Resource Perspective: Family Community and Connections, and Discontinuous}

Technology Adoption. Maintaining the relational intensity among employees in the family firm (referred to as community in König et al.) is an important resource. However, non-family employees do not necessarily share emotional ties and identity with the family (Verbeke and Kano, 2012). Community may therefore depend upon the extent to which the controlling family builds more rather than less transparent and formalized human resource policies concerning hiring, promotion, and compensation. This means that high concerns for community may lead to higher instead of lower formalization as suggested by König et al. Community also suggests that non-family employees may be given more power and legitimacy in decision-making, which could either increase political resistance or efforts to find common ground among family and non-family stakeholders. Consequently, commitment to the status quo or to changing the status quo could increase, thereby further entrenching or overthrowing the mental models of family owners and managers. Likewise, an increase in community could be positively or negatively related to the desire to preserve existing assets past the time when they add economic value to the firm. Overall, given that an increase in community implies compatibility between the family and internal non-family stakeholders, its effect upon the aggressiveness, stamina, and flexibility of the adoption of discontinuous technology is likely related to whether the family emphasizes short-term command or long-term continuity.

Proposition 3: If command prevails over continuity in family firm decision making, the relationship between the degree of community and the adoption of discontinuous technologies is negative; if continuity prevails over command, the relationship is positive.

Finally, family firms vary widely in terms of organizational resources, such as their connections with customers, suppliers, competitors, government, and other stakeholders. Building connections with external stakeholders can provide industry-specific knowledge that 
help family firms more quickly recognize the need to adopt discontinuous technologies. Such connections may also increase access and reduce the cost of external financial resources, which could increase their use and decrease the perceived risk of adopting discontinuous technologies. Connections with external stakeholders should expose family owners and managers to new knowledge and this will likely reduce the rigidity of the mental models of decision makers, thereby increasing flexibility. Thus, connections should be positively associated with many of the factors that Konig et al. suggest will increase the adoption of discontinuous technologies.

Proposition 4: The relationship between the external connections of family owners and managers and the adoption of discontinuous technologies is positive.

\section{Preference Reversals in Family Firms and Discontinuous Technology Adoption.}

Commenting on the study by Chrisman and Patel (2012), König et al. argue that "threat perception in family-influenced firms could result in lower investments in discontinuous technologies" (2013: 436). This argument is partially built upon the belief that family influence increases the rigidity of the mental models of family decision makers and that this rigidity will reduce flexibility in spite of the lower formalization of the governance structures of family firms. In other words, although König et al. seem to take for granted the predominance of command, they do not allow for situational factors that lead to preference reversals. As noted by GomezMejia et al. (2010), performance hazards that endanger the family's socioemotional wealth often lead to actions that are diametrically opposed to the actions one might observe in other more stable and favorable situations, i.e., risk-seeking behavior replaces risk-averse behavior. Indeed, Patel and Chrisman's (forthcoming) recent work shows that when performance is below aspirations, family firms not only invest more in R\&D than non-family firms, they also switch their emphasis from variance-reducing, exploitative investments to mean-enhancing, exploratory investments. Similarly, Sirmon et al. (2008) show that family firms embrace risky innovation and 
internationalization strategies in response to threats of imitation. Finally, the qualitative study by Kotlar and De Massis (2013) suggests that family firms re-frame their organizational goals when intra-family succession is imminent.

Again, heterogeneous behavior emanating from preference reversals challenges a strictly linear and strongly interdependent interpretation of the dimensions of family influence. Indeed, contrary to König et al.'s arguments, the governance structure of family firms enables them the flexibility to rapidly recognize and aggressively seize opportunities or counter threats (Carney, 2005), and the literature shows that they will do so when the survival of the firm as an economic and/or family-influenced entity is considered to be in jeopardy. Hence:

Proposition 5: The relationship between family command and the adoption of discontinuous technologies turns positive in the wake of situations (e.g., performance hazard, exogenous shocks, and generational transitions) that may threat the family's socio-emotional wealth.

\section{Conclusions}

Family firms are different as well as more heterogeneous than non-family firms because they have a unique and expanded goal set (Chrisman and Patel, 2012; Kotlar and De Massis, 2013). These goals can change according to the whims of the family, especially when facing critical situations such as performance hazards, exogenous shocks, and generational transitions. Family firms are also heterogeneous because their governance structures permit great flexibility and unusual fiat, but vary in their effect on decision making according to factors that affect the firm's goal structure, such as the extent of inter- and intra-generational family ownership (Chrisman et al., 2012). Finally, variations in the resources and capabilities family members bring, individually and collectively, to the firm will also generate heterogeneity (Carney, 2005) as they determine the goals that can or cannot be achieved and the opportunities than can or cannot be pursued. 
König et al.'s model is not general enough to accommodate variations in family business goals, governance structures, resources, and idiosyncratic situational factors that can affect strategic decisions regarding innovation such as the adoption of discontinuous technologies. However, as the field of family business moves forward, the sources and consequences of family firm heterogeneity need to be identified and understood. This conceptual note only begins to tackle this complex issue but hopefully illustrates some of the opportunities to increase knowledge about the family form of organization that are available if these basic considerations are kept in mind in future research efforts. 


\section{References}

Berrone, P., C. Cruz, L. R. Gomez-Mejia. 2012. "Socioemotional wealth in family firms: Theoretical dimensions, assessment approaches, and agenda for future research." Family Business Review 25 (3): 258-279.

Carney, M. 2005. "Corporate governance and competitive advantage in family-controlled firms." Entrepreneurship Theory and Practice 29 (3): 249-265.

Chrisman, J. J., J. H. Chua, A. W. Pearson, and T. Barnett. 2012. "Family involvement, family influence, and family centered non economic goals in small firms." Entrepreneurship Theory and Practice 36 (2): 267-293.

Chrisman, J. J., and P. J. Patel. 2012. "Variations in R\&D investments of family and non-family firms: Behavioral agency and myopic loss aversion perspectives." Academy of Management Journal 55 (4): 976-997.

De Massis, A., J. Kotlar, J. H. Chua, and J. J. Chrisman. Forthcoming. "Ability and willingness as sufficiency conditions for family-oriented particularistic behavior: Implications for theory and empirical studies." Journal of Small Business Management.

Gedajlovic, E., and M. Carney. 2010. "Markets, hierarchies, and families: Toward a transaction cost theory of the family firm." Entrepreneurship Theory and Practice 34 (6): 1145-1172.

Gersick, K. E., J. A. Davis, M. M. Hampton, and I. Lansberg. 1997. Generation to generation: Life cycles of the family business. Boston, MA: Harvard Business Press.

Gómez-Mejía, L. R., M. Makri, and M. Larraza-Kintana. 2010. "Diversification decisions in family-controlled firms." Journal of Management Studies 47 (2): 223-252.

Ilias, N. 2006. "Families and firms: Agency costs and labor market imperfections in sialkot's surgical industry." Journal of Development Economics 80 (2): 329-349.

König, A., N. Kammerlander, and A. Enders. 2013. “The family innovator’s dilemma: How family influence affects the adoption of discontinuous technologies by incumbent firms." Academy of Management Review 38 (3): 418-441.

Kotlar, J., and A. De Massis. 2013. "Goal setting in family firms: Goal diversity, social interactions, and collective commitment to family-centered goals." Entrepreneurship Theory and Practice 37 (6): 1263-1288.

Luo, X. R., and C. N. Chung. 2013. "Filling or abusing the institutional void? Ownership and management control of public family businesses in an emerging market." Organization Science 24 (2): 591-613. 
Miller, D., and I. Le Breton-Miller. 2005. Managing for the long run. Boston, MA: Harvard Business School Press.

Patel, P. C., and J. J. Chrisman. Forthcoming. "Risk abatement as a strategy for R\&D investments in family firms." Strategic Management Journal.

Sirmon, D. G., J. L. Arregle, M. A. Hitt, and J. W. Webb. 2008. "The role of family influence in firms' strategic responses to threat of imitation." Entrepreneurship Theory and Practice 32 (6): 979-998.

Verbeke, A., and L. Kano. 2012. "The transaction cost economics theory of the family firm: Family-based human asset specificity and the bifurcation bias." Entrepreneurship Theory and Practice 36 (6): 1183-1205.

Zellweger, T. M., F. W. Kellermanns, J. J. Chrisman, and J. H. Chua. 2012. "Family control and family firm valuation by family CEOs: The importance of intentions for transgenerational control." Organization Science 23 (3): 851-868.

Zellweger, T. M., and R. S. Nason. 2008. “A stakeholder perspective on family firm performance.” Family Business Review 21 (3): 203-216. 